\title{
Cardiomyocyte-Derived Mitochondrial Superoxide Causes Myocardial Electrical Remodeling by Downregulating Potassium Channels and Related Molecules
}

\author{
Sayaka Kurokawa, MD; Shinichi Niwano, MD; Hiroe Niwano, MD; Masami Murakami, MD; \\ Shoko Ishikawa, MD; Yoshihiko Masaki; Hideaki Tamaki, PhD; Toshihiko Toda; \\ Yoshihiro Noda; Takahiko Shimizu, PhD; Tohru Izumi, MD; Junya Ako, MD
}

Background: This study was designed to investigate the role of a primary hyperoxidative stress in myocardial electrical remodeling using heterozygous heart/muscle-specific manganese superoxide dismutase-deficient $(\mathrm{H} / \mathrm{M}$ Sod $2^{+/-}$) mice treated with L-buthionine-sulfoximine (BSO).

Methods and Results: Both H/M-Sod2+/- and wild-type (WT) mice were treated with intra-peritoneal BSO or saline for 7 days, and divided into 4 groups: H/M-Sod2+/-+BSO, WT+BSO, H/M-Sod2 ${ }^{+/-}$control, and WT control. The ventricular effective refractory period (ERP) and the monophasic action potential duration (MAPD) were determined. Levels of oxidative stress, potassium channel-related molecules, and $\mathrm{K}^{+}$channel-interacting protein-2 (KChIP2) were also evaluated. The H/M-Sod2+/-+BSO group exhibited markedly prolonged MAPD 20, MAPD $_{90}$ and ERP in comparison with the other groups (MAPD $20: 14 \pm 1$ vs. $11 \pm 1 \mathrm{~ms}$, MAPD90: $77 \pm 7$ vs. $58 \pm 4 \mathrm{~ms}$, ERP: $61 \pm 6$ vs. $41 \pm 3 \mathrm{~ms}$, $\mathrm{H} / \mathrm{M}-\mathrm{Sod}_{2}{ }^{+-}+\mathrm{BSO}$ vs. WT control; $\left.\mathrm{P}<0.05\right)$. Mitochondrial superoxide and hydrogen peroxide formation in the myocardium increased in the $\mathrm{H} / \mathrm{M}-\mathrm{Sod} 2^{+/-}+\mathrm{BSO}$ group in comparison with the WT+BSO group $(\mathrm{P}<0.05)$. Real-time RT-PCR and Western blotting revealed that Kv4.2 expression was downregulated in both BSO-treated groups, whereas KChIP2 expression was downregulated only in the $\mathrm{H} / \mathrm{M}-\mathrm{Sod} 2^{+-}+\mathrm{BSO}$ group $(\mathrm{P}<0.05)$.

Conclusions: BSO treatment caused hyperoxidative stress in the myocardium of $\mathrm{H} / \mathrm{M}-\mathrm{Sod} 2^{+/-}$mice. Changes in the expression and function of potassium channels were considered to be involved in the mechanism of electrical remodeling in this model. (Circ J 2014; 78: 1950-1959)

Key Words: Electrical remodeling; K+ channel-interacting protein-2 (KChIP2); Potassium channel; Reactive oxygen species; Superoxide dismutase 2 (Sod2)

$\mathbf{O}$ xidative stress has been considered to play a causative role in various cardiovascular diseases, such as reperfusion injury in ischemia, ${ }^{1-3}$ and myocardial injury in heart failure. ${ }^{4,5}$ More recently, a direct relationship between oxidative stress and electrical remodeling has also been suggested. ${ }^{6}$ We have previously documented that primary hyperoxidative stress produced electrical remodeling, which is characterized by MAPD 90 prolongation, ERP shortening, and increased ventricular vulnerability in the glutathione-depleted systemic hyperoxidative rat. ${ }^{7}$ In that model, the hyperoxidative stress was produced by systemic glutathione-depletion, which was induced by the administration of L-buthionine-sulfoximine (BSO). In the previous model, ${ }^{7}$ the hyperoxidative stress was systemic and not restricted to the myocardial tissue, and primary changes due to its effects on the myocardium and secondary changes due to its effect on other organs and tissues such as neurohumoral reactions could not be distinguished. Therefore, the model is incomplete and not appropriate for evaluating the primary effect of oxidative stress on the electrical properties of the myocardium.

\section{Editorial $p 1834$}

Superoxide dismutase $2(\operatorname{Sod} 2)$ is one of the enzymes that

Received December 26, 2013; revised manuscript received April 2, 2014; accepted April 9, 2014; released online May 23, 2014 Time for primary review: 26 days

Department of Cardiovascular Medicine (S.K., S.N., M.M., S.I., Y.M., T.I., J.A.), Department of Anatomy (H.T.), Kitasato University School of Medicine, Sagamihara; Department of Education, Tamagawa University, College of Education, Tokyo (H.N.); Molecular Gerontology, Tokyo Metropolitan Institute of Gerontology, Tokyo (T.T., Y.N., T.S.); and Department of Advanced Aging Medicine, Chiba University Graduate School of Medicine, Chiba (T.T., T.S.), Japan

Mailing address: Sayaka Kurokawa, MD, Department of Cardiovascular Medicine, Kitasato University School of Medicine, 1-15-1 Kitasato, Minami-ku, Sagamihara 252-0374, Japan. E-mail: ksayaka@med.kitasato-u.ac.jp

ISSN-1346-9843 doi:10.1253/circj.CJ-13-1587

All rights are reserved to the Japanese Circulation Society. For permissions, please e-mail: cj@j-circ.or.jp 
eliminates reactive oxygen species (ROS) in mitochondria, converting superoxide $\left(\mathrm{O}_{2}{ }^{-}\right)$to hydrogen peroxide $\left(\mathrm{H}_{2} \mathrm{O}_{2}\right)$. Homozygous heart/muscle-specific manganese superoxidedeficient (H/M-Sod2 $\left.{ }^{--}\right)$mice have been reported to exhibit a dilated cardiomyopathy-like condition with dilated dimensions, a lower ejection fraction of the left ventricle and the destruction of myocardial tissue. ${ }^{8}$ They exhibit a 12.3 -fold larger fibrotic area and a decreased expression of connexin 43 in their myocardium in comparison with age-matched wild-type (WT) mice. ${ }^{9}$ In contrast, heterozygous heart/muscle-specific manganese superoxide-deficient (H/M-Sod2 ${ }^{+-}$) mice exhibit no obvious difference in phenotypes in comparison with WT mice under normal circumstances, but exhibit an excessive response to hyperoxidative conditions, such as reperfusion injury..$^{10}$ However, the arrhythmogenicity of the response to the hyperoxidative state in these mice is unclear. In this study, we used this heterozygous (H/M-Sod2 $\left.{ }^{+-}\right)$mouse and a protocol designed to clarify the role of primary hyperoxidative stress derived from, and restricted to, the myocardium in the progression of electrical remodeling without apparent structural heart disease.

\section{Methods}

\section{Animals and Study Protocol}

We used H/M-Sod $2^{+/-}$mice, produced by crossbreeding H/MSod $2^{--}$mice with WT mice. H/M-Sod2 $2^{--}$mice were a gift from Dr Shimizu, Tokyo Metropolitan Institute of Gerontology. H/M-Sod2 $2^{-1-}$ mice were produced by crossbreeding Sod2 $2^{\text {lox/lox }}$ mice with muscle creatine kinase (MCK)-Cre transgenic mice using in vitro fertilization techniques. Genotyping was performed by tail DNA polymerase chain reaction, as described previously (Figure S1). ${ }^{8}$ Nine-week-old H/M-Sod2 ${ }^{+/}$and WT mice were treated with BSO or saline for 7 days. The dose of $\mathrm{BSO}$ was $1.5 \mathrm{mmol} / \mathrm{kg}$ and it was intraperitoneally injected twice a day in the BSO-treated groups. ${ }^{11}$ In the control groups, saline of an equal volume was injected in the same manner. The mice were divided into 4 groups: heterozygous mice treated with BSO (H/M-Sod2 $\left.2^{+-}+\mathrm{BSO}, \mathrm{n}=38\right)$, WT mice treated with BSO (WT+BSO, $n=40)$, heterozygous mice treated with saline as a control (H/M-Sod2 ${ }^{+/-}$control, $\left.n=38\right)$, and a WT control $(n=40)$. On day 7 , the parameters described below were evaluated and compared among the 4 groups. All studies were performed in accordance with the Guide for the Care and Use of Laboratory Animals published by the US National Institutes of Health (NIH Publication No. 85-23, revised 1996) and the Ethics Committee of Kitasato University School of Medicine.

\section{Histopathological Findings}

Body weights were measured every day. On day 7, the mice were sacrificed under anesthesia and whole hearts were excised for further analysis. The heart weight (HW) was measured. In randomly selected mice, the heart was transversely sliced and fixed in $10 \%$ formalin, embedded in paraffin, and stained with hematoxylin-eosin for histological evaluation.

\section{Physiological Evaluations}

The echocardiography was performed using ultrasonography (ProSound SSD-4000; ALOKA Co, Ltd, Tokyo, Japan) with a 4-14 MHz linear probe on day 7 of the study protocol. The heart was imaged in the 2-dimensional parasternal short-axis view, and a M-mode echocardiogram of the left ventricle was recorded at the level of the papillary muscle. Left ventricular diastolic and systolic dimensions (LVDd and LVDs), thickness of the interventricular septum (IVSth), thickness of the posterior wall (PWth) and left ventricular ejection fraction (LVEF) were obtained from the M-mode image.

On day 7, an electrophysiological evaluation was also performed in randomly selected mice $\left(\mathrm{H} / \mathrm{M}-\operatorname{Sod}_{2}{ }^{+/}+\mathrm{BSO}: \mathrm{n}=8\right.$, WT+BSO: $\mathrm{n}=6, \mathrm{H} / \mathrm{M}-$ Sod $^{+/-}$control: $\mathrm{n}=8$, and WT control: $\mathrm{n}=6)$. Under interperitoneal anesthesia with sodium pentobarbital $(50 \mathrm{mg} / \mathrm{kg}$ for control groups, and $25 \mathrm{mg} / \mathrm{kg}$ for BSOtreated groups) and artificial ventilation, the heart was exposed through a median sternotomy. The depth of the anesthesia was controlled during the study by additional intravenous sodium pentobarbital so as not to exceed a heart rate of 400 beats $/ \mathrm{min}$. A pair of tungsten needle electrodes $(\varphi 0.2 \mathrm{~mm})$ was made to puncture all layers of the ventricle from the epicardium to the endocardium, and was used for the electrophysiological evaluation, as described previously. ${ }^{7,12}$ The ventricular effective refractory period (ERP) and the duration of monophasic action potential (MAPD) were evaluated. ${ }^{7,12}$ To evaluate the ERP, a single extra stimulus was delivered after 8 basic stimuli with a cycle length of $150 \mathrm{~ms}$. The coupling interval of the extra stimulus was shortened in 2-ms steps until it reached ventricular refractoriness. The MAPD was determined as the interval between the onset of the MAP trace and the 20\% (MAPD 20$)$ and $90 \%$ (MAPD90) repolarization times.

\section{Measurement of Total Glutathione Levels in Cardiac Tissue, and Serum Derivatives of Reactive Oxygen Metabolites (d-ROM)}

Cardiac tissues were homogenized in a phosphate-buffered saline solution, and interfering proteins were removed using $5 \%$ metaphosphoric acid. The total amount of glutathione (reduced and oxidized) in the myocardium was measured using the NWLSS ${ }^{\mathrm{TM}}$ Glutathione Assay (Northwest Life Science Specialties, LLC, Vancouver, WA, USA), and the data was corrected by the protein level in each sample. The serum levels of d-ROM were measured using the Free Radical Analytical System 4 (FRAS4; H\&D srl, Parma, Italy). ${ }^{13}$

\section{Expression of $\mathrm{O}_{2}-$ and $\mathrm{H}_{2} \mathrm{O}_{2}$ in the Myocardium}

The mitochondrial fraction of the myocardium was isolated using a Mitochondria Isolation $\mathrm{Kit}^{\mathrm{TM}}$ (Sigma, St Louis, MO, USA). The purity of the mitochondrial fraction was verified by 5, 5', 6, 6'-tetrachloro-1, 1', 3, 3'-tetraethyl-benzimidazolylcarbocyanine iodide (JC-1) uptake in mitochondria. JC-1 uptake was measured using the JC-1 stain and JC-1 Assay Buffer in the Mitochondria Isolation $\mathrm{Kit}^{\mathrm{TM}} \cdot \mathrm{O}_{2}{ }^{-}$- formation was measured using the chemiluminescent probe, MPEC (2-methyl-6- $p$-methoxyphenylethynylimidazopyrazinone; ATTO, Tokyo, Japan), by a luminometer (Lumat LB 9507; Berthold Technologies, Bad Wildbad, Germany). ${ }^{9} \mathrm{H}_{2} \mathrm{O}_{2}$ generation was measured by using Amplex Red ${ }^{\mathrm{TM}}$ (Molecular Probes, Eugene, OR, USA). $\mathrm{H}_{2} \mathrm{O}_{2}$ formation was measured fluorometrically (excitation: $530 \mathrm{~nm}$, emission: $590 \mathrm{~nm}$ ) over $30 \mathrm{~min}$ at $37^{\circ} \mathrm{C}$ in a SpectraMax Gemini XS (Molecular Devices, Sunnyvale, CA, USA). Fluorescence units were converted using the standard curve for a known concentration of $\mathrm{H}_{2} \mathrm{O}_{2}$. The results are expressed as pmol $\mathrm{H}_{2} \mathrm{O}_{2} / \mathrm{min} / \mathrm{mg}$ protein. ${ }^{9}$ To evaluate the in situ expression of ROS, fluorescent dihydroethydium (DHE, $10 \mu \mathrm{mol} / \mathrm{L}$; Sigma) staining and 5-(and 6-)chloromethyl-2', 7'-dichlorodihydrofluorescein diacetate, acetyl ester (DCF-DA, $10 \mu \mathrm{mol} / \mathrm{L}$; Molecular Probes, Eugene, OR, USA) staining were performed. The specificity of DHE and DCF-DA signals for $\mathrm{O}_{2}{ }^{-}$and $\mathrm{H}_{2} \mathrm{O}_{2}$ detection was confirmed by pre-incubation with their inhibitor, polyethylene glycol-superoxide dismutase (PEG-SOD; 500U/ml, Sigma) and PEG-catalase (350U/ml, Sigma), respectively. ${ }^{14}$ DHE or DCF-DA images were obtained with a laser-scanning confocal microscope (LMS710; Carl Zeiss MicroImaging Co, 


\begin{tabular}{|lcccc|}
\hline Table 1. Body Weight and Heart Weight & & & & \\
Body weight (g) & H/M-Sod2++-BSO & WT+BSO & H/M-Sod2+/- control & WT control \\
Day 0 & $21.8 \pm 0.8$ & $22.1 \pm 0.7$ & $21.8 \pm 0.8$ & $22.1 \pm 0.8$ \\
Day 1 & $21.9 \pm 0.9$ & $22.0 \pm 0.7$ & $22.1 \pm 0.8$ & $22.3 \pm 0.8$ \\
Day 2 & $21.9 \pm 0.8$ & $22.1 \pm 0.7$ & $22.0 \pm 0.8$ & $22.2 \pm 0.8$ \\
Day 3 & $21.8 \pm 0.8$ & $22.1 \pm 0.7$ & $22.1 \pm 0.8$ & $22.3 \pm 0.8$ \\
Day 4 & $21.9 \pm 0.8$ & $22.1 \pm 0.6$ & $22.1 \pm 0.8$ & $22.3 \pm 0.8$ \\
Day 5 & $20.8 \pm 0.8$ & $21.3 \pm 0.6$ & $22.0 \pm 0.7$ & $22.5 \pm 0.8$ \\
Day 6 & $19.9 \pm 0.9^{*, \pm}$ & $20.7 \pm 0.6$ & $22.4 \pm 0.7$ & $22.5 \pm 0.8$ \\
Day 7 & $19.7 \pm 0.8^{*, \pm}$ & $20.7 \pm 0.6$ & $22.2 \pm 0.7$ & $22.6 \pm 0.8$ \\
Heart weight (g) & & & & \\
Day 7 & $0.098 \pm 0.003$ & $0.098 \pm 0.002$ & $0.099 \pm 0.003$ & $0.103 \pm 0.004$ \\
\hline
\end{tabular}

${ }^{*} \mathrm{P}<0.05$ vs. WT control. $\neq \mathrm{P}<0.05$ vs. $\mathrm{H} / \mathrm{M}-\mathrm{Sod} 2^{+/-}$control.

H/M-Sod2+/-BSO: $n=18$, WT+BSO: $n=19, H / M-S o d 2^{+/-}$control: $n=19$, WT control: $n=20$.

BSO, L-buthionine-sulfoximine; H/M-Sod2+/, heterozygous heart/muscle-specific manganese superoxide dismutasedeficient mice; WT, wild type.
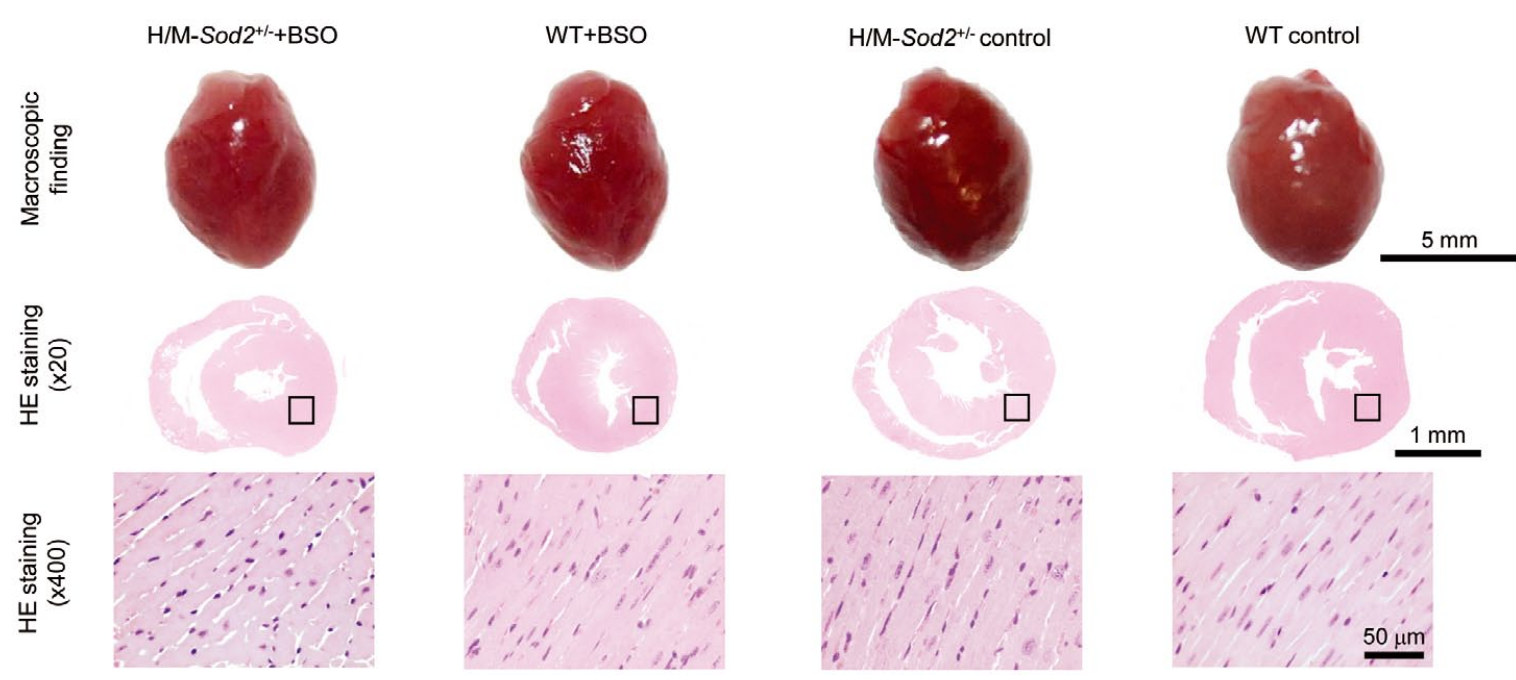

Figure 1. Histopathological findings. Macroscopic findings and hematoxylin-eosin (HE) staining of the myocardium (macroscopic findings: scale bar $=5 \mathrm{~mm}, \times 20$ : scale bar $=1 \mathrm{~mm}, \times 400$ : scale bar $=50 \mu \mathrm{m}$ ). On HE staining, partial misalignment of cardiomyocytes was observed in the H/M-Sod2+/- BSO group. See text for discussion. H/M-Sod2+-- heterozygous heart/muscle-specific manganese superoxide dismutase-deficient mice; BSO, L-buthionine-sulfoximine.

Ltd, Oberkochen, Germany). Fluorescence was quantified by ZEN 2008 image analysis software (Carl Zeiss MicroImaging Co, Ltd).

\section{Plasmid Construction and Quantitative Real-Time RT-PCR}

Total RNA was prepared from the left ventricular free wall using a total RNA isolation kit (SV Total RNA Isolation System; Promega, Madison, WI, USA). cDNA was synthesized from $3 \mu \mathrm{g}$ of total RNA with reverse transcriptase (SuperScript ${ }^{\mathrm{TM}} \mathrm{III}$ Reverse Transcriptase; Invitrogen Corp, Carlsbad, CA, USA) in a final volume of $20 \mu \mathrm{l}$. The mRNA levels were determined by quantitative real-time RT-PCR, with the primers shown in Table S1. The amplified DNA was inserted into the PGEM $^{\circledR}-\mathrm{T}$ Easy Vector (Promega). The recombinant plasmid was isolated after transforming it into JM109 competent cells using a Wizard ${ }^{\circledR}$ Plus SV Minipreps DNA Purification System (Promega). The plasmid was used as the standard sample after the sequence identities were confirmed. Real-time RT-PCR was performed with pPCR MasterMix Plus for SYBR ${ }^{\circledR}$ Green I (Eurogentec s.a., Seraing, Liege, Belgium) and the CFD 3240 Chromo4 $^{\mathrm{TM}}$ Detection System (BioRad Lab, Inc, Richmond, CA, USA), as described previously. ${ }^{7,12}$ As the internal controls, the levels of glyceraldehyde-3-phosphate dehydrogenase (GAPDH) were also evaluated.

\section{Western Blot Analysis}

Cardiac tissues were homogenized in ice-cold lysis buffer containing $50 \mathrm{mmol} / \mathrm{L}$ Tris- $\mathrm{HCl}$ (pH 7.5), $1 \mathrm{mmol} / \mathrm{L}$ EGTA, $150 \mathrm{mmol} / \mathrm{L} \mathrm{NaCl}, 0.25 \% \mathrm{SDC}, 1 \mathrm{mmol} / \mathrm{L}$ sodium orthovanadate, $1 \%$ Triton X-100, $2 \mu \mathrm{g} / \mathrm{ml}$ aprotinin, $1 \mathrm{mmol} / \mathrm{L}$ PMSF, and $5 \mu \mathrm{g} / \mathrm{ml}$ leupeptin. The samples were used for Western blotting with antibodies for Sod2 (Stressgen, Victria, Canada), Kv4.2/4.3 (Santa Cruz Biotechnology, Inc, Santa Cruz, CA, USA), ether-a-go-go-related gene (erg) 1/2/3 (Santa Cruz 


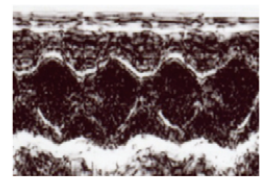

$\mathrm{H} / \mathrm{M}-\mathrm{Sod} 2^{++-}+\mathrm{BSO}$

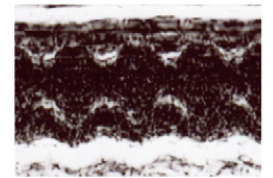

WT+BSO

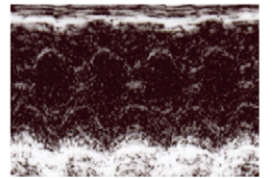

H/M-Sod2 ${ }^{+/-}$control

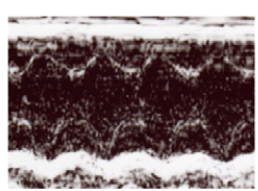

WT control
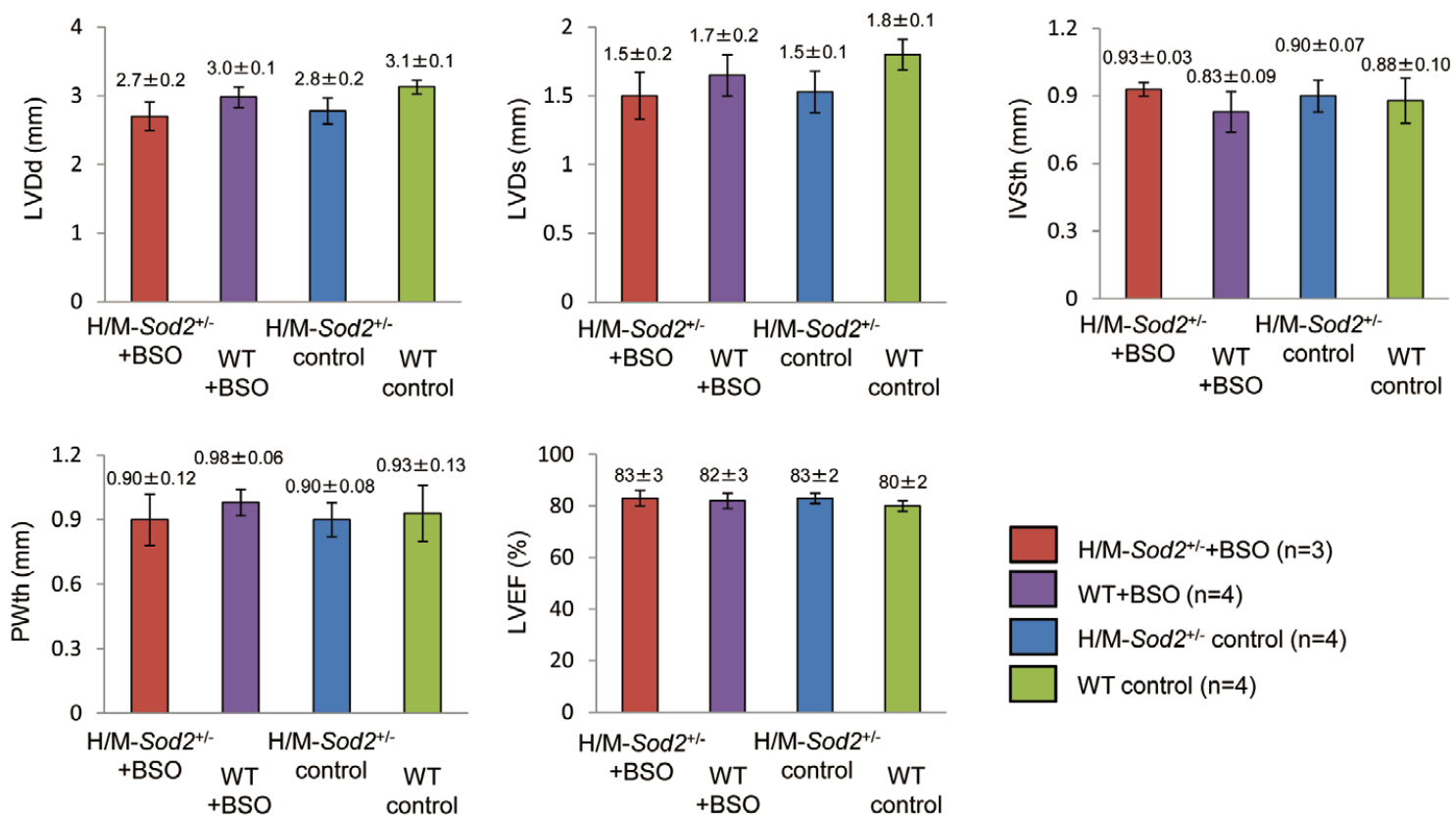

Figure 2. Echocardiographic data. The findings of the echocardiographic analysis on day 7. H/M-Sod2+/- groups exhibited a normal size, wall thickness, and ejection fraction in the left ventricles even in the BSO-treated group. There were no differences among the 4 groups in terms of echocardiographic parameters (H/M-Sod2 $2^{+-}+B S O: n=3$, WT+BSO: $n=4, H / M-S o d 2^{+/-}$control: $n=4$, WT control: $\mathrm{n}=4$ ). See text for discussion. $\mathrm{H} / \mathrm{M}$-Sod2+-, heterozygous heart/muscle-specific manganese superoxide dismutasedeficient mice; BSO, L-buthionine-sulfoximine; WT, wild type.

Biotechnology, Inc), $\mathrm{K}^{+}$channel-interacting protein-2 (KChIP2) (ABGENT, San Diego, CA, USA), connexin 43 (Santa Cruz Biotechnology, Inc), and GAPDH $\left(\right.$ GeneTex $^{\circledR}$, Inc, Irvine, CA, USA). After development with the ECL detection kit (Immobilon Western Chemiluminescent HRP Substrate; Millipore Corporation, Billerica, MA, USA), the density of each band in the digitized images was measured using the public domain NIH Image program. The expression levels were normalized to those of the WT control group.

\section{Statistical Analysis}

All values are expressed as the mean \pm SE. The basic comparative statistics were produced with a one-way ANOVA or unpaired t-test. The statistical analysis was performed with JMP 6 software for Windows (SAS Institute Inc, Cary, NC, USA). A P value of $<0.05$ was considered significant.

\section{Results}

\section{Histopathological Findings}

Table 1 shows changes in the body weights of mice along the time-course and HW on day 7. There were no differences in body weight among the 4 groups on days $0-5$, but the H/MSod $2^{+/-}+\mathrm{BSO}$ group weighed less than the control groups on days 6 and 7. HW showed no significant difference among the
4 groups. Figure 1 shows representative examples of hearts from the 4 groups. Isolated hearts did not show any differences in terms of macroscopic findings among the 4 groups. HE staining revealed no apparent fibrosis or degeneration of myocytes; however, partial misalignment of myocytes was observed in the H/M-Sod2 $2^{+-}+\mathrm{BSO}$ group.

\section{Physiological Findings}

In the echocardiography findings on day 7 , there was no pathological finding in any mice. The echocardiographic data, that is, LVDd, LVDs, IVSth, PWth and LVEF, did not exhibit any differences among the 4 groups (Figure 2).

Figure 3 shows the electrophysiological parameters on day 7. Representative MAP traces of the 4 groups are exhibited in Figure 3A. The MAP duration tended to be prolonged in $\mathrm{H} / \mathrm{M}-$ Sod2 $2^{+-}+\mathrm{BSO}$ mice compared with the others. In the electrophysiological study, MAPD 20 was markedly prolonged in both BSO-treated groups, that is, H/M-Sod2 $2^{+/-}+\mathrm{BSO}$ and $\mathrm{WT}+\mathrm{BSO}$ groups (Figure 3B; H/M-Sod $2^{+/-}+\mathrm{BSO}$ vs. WT control, $\mathrm{P}=0.013$; WT+BSO vs. WT control, $\mathrm{P}=0.021$, respectively). In contrast, MAPD 90 was prolonged only in the H/M-Sod2 ${ }^{+/-}$ $+\mathrm{BSO}$ group (Figure 3C; H/M-Sod2 ${ }^{+-}+\mathrm{BSO}$ vs. WT+BSO, $\mathrm{P}=0.039 ; \mathrm{H} / \mathrm{M}-S_{\text {Sod }}{ }^{+/-}+\mathrm{BSO}$ vs. H/M-Sod2 ${ }^{+/-}$control, $\mathrm{P}=0.027$; $\mathrm{H} / \mathrm{M}-S_{\text {Sod }} 2^{+/}+\mathrm{BSO}$ vs. WT control, $\mathrm{P}=0.012$, respectively). Similar to MAPD90, ERP was prolonged only in the H/M- 

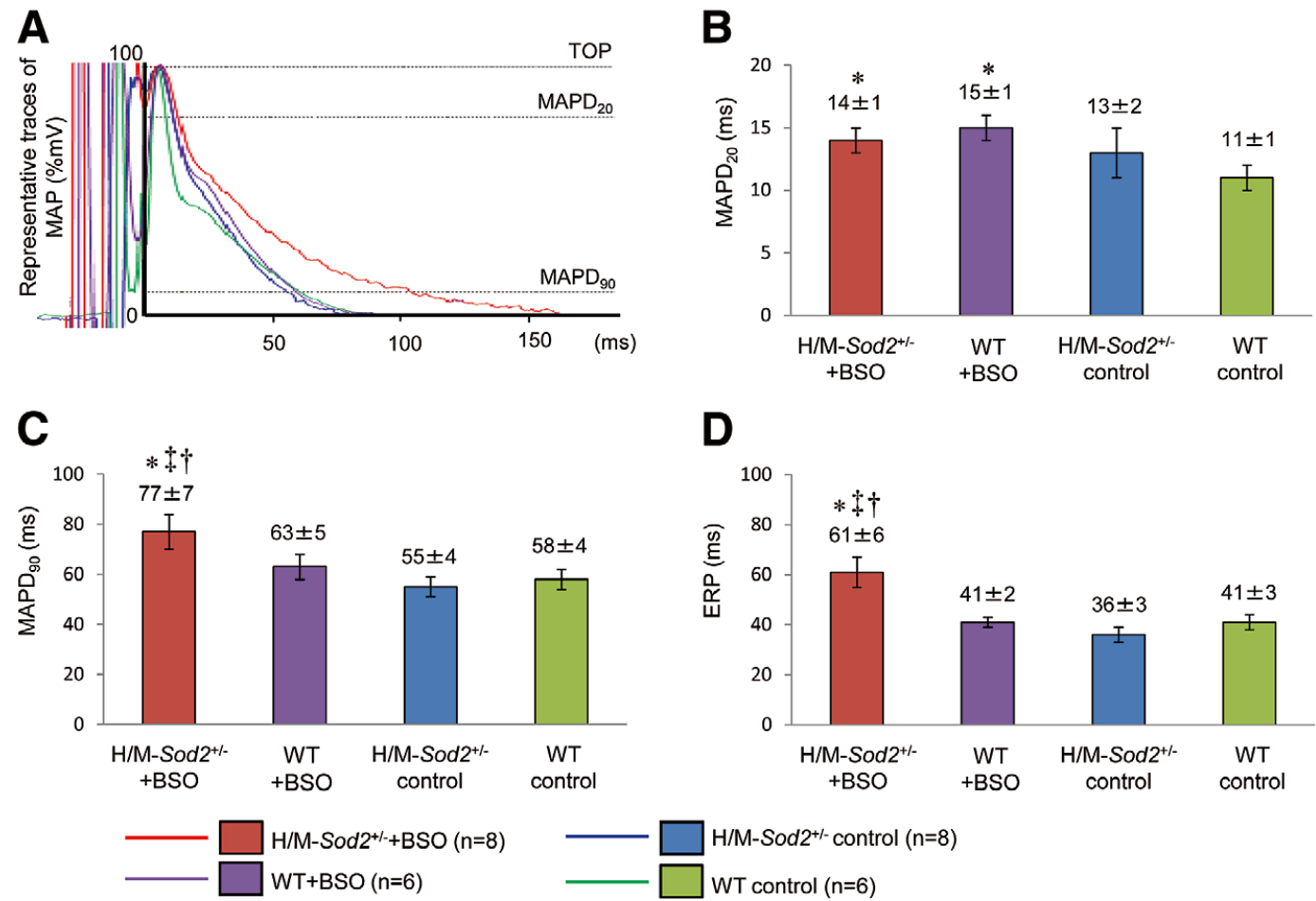

D

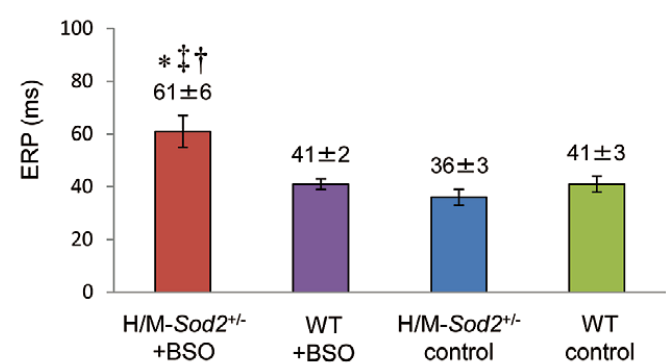

$\mathrm{H} / \mathrm{M}-\mathrm{Sod}^{+1-}$ control $(\mathrm{n}=8)$

Figure 3. Electrophysiological parameters. The changes in electrophysiological parameters. (A) It shows representative traces of MAP. (B) MAPD 20 was markedly prolonged in the H/M-Sod2+-+BSO and WT+BSO groups. ${ }^{*} \mathrm{P}<0.05$ vs. WT control. (C) MAPD90 was markedly prolonged in the $\mathrm{H} / \mathrm{M}-\mathrm{Sod} 2^{+-}+\mathrm{BSO}$ group in comparison with the other 3 groups. ${ }^{\mathrm{P}}<<0.05 \mathrm{vs}$. WT+BSO. $\neq \mathrm{P}<0.05$ vs. H/M-Sod2+/- control. * $\mathrm{P}<0.05$ vs. WT control. (D) ERP was prolonged in the $\mathrm{H} / \mathrm{M}-\mathrm{Sod} 2^{+1-}+\mathrm{BSO}$ group in comparison with the other 3 groups. ${ }^{\dagger} \mathrm{P}<0.05$ vs. WT+BSO. $\neq \mathrm{P}<0.05$ vs. $\mathrm{H} / \mathrm{M}-\mathrm{Sod} 2^{+/-}$control. ${ }^{*} \mathrm{P}<0.05$ vs. WT control. See text for discussion. MAP, monophasic action potential; H/M-Sod2+/, heterozygous heart/muscle-specific manganese superoxide dismutase-deficient mice; BSO, L-buthionine-sulfoximine; WT, wild type; ERP, effective refractory period.

\begin{tabular}{|c|c|c|c|c|}
\hline & $\begin{array}{l}\text { Total glutathione } \\
\text { (mmol/g) }\end{array}$ & $\begin{array}{l}\text { d-ROM } \\
\text { (U.CARR) }\end{array}$ & $\begin{array}{l}\mathrm{O}_{2} \cdot-\text { formation [Relative } \\
\text { chemiluminescence } \\
\text { intensity }(\%)]\end{array}$ & $\begin{array}{c}\mathrm{H}_{2} \mathrm{O}_{2} \text { formation } \\
\text { (pmol/min/mg } \\
\text { protein) }\end{array}$ \\
\hline $\mathrm{H} / \mathrm{M}-\mathrm{Sod} 2^{+/-}+\mathrm{BSO}$ & $2.1 \pm 0.5^{\star}, \ddagger$ & $124.9 \pm 3.2^{\star, \neq}$ & $131 \pm 12^{\dagger}$ & $421 \pm 24^{\star}, \dagger$ \\
\hline WT+BSO & $2.1 \pm 0.5^{\star, \ddagger}$ & $126.1 \pm 6.6$ & $98 \pm 11$ & $337 \pm 9$ \\
\hline $\mathrm{H} / \mathrm{M}-$ Sod2 $^{+/-}$control & $12.4 \pm 1.0$ & $109.3 \pm 3.5$ & $114 \pm 14$ & $354 \pm 25$ \\
\hline WT control & $12.5 \pm 0.4$ & $108.3 \pm 4.4$ & $100 \pm 16$ & $325 \pm 33$ \\
\hline
\end{tabular}

${ }^{*} \mathrm{P}<0.05$ vs. WT control. ${ }^{\mathrm{P}}<0.05$ vs. $\mathrm{H} / \mathrm{M}-\mathrm{Sod} 2^{+/-}$control. ${ }^{\mathrm{t} P}<0.05$ vs. WT+BSO.

Total glutathione: $n=5$ in each group.

d-ROM: H/M-Sod2+-+BSO: $n=10$, WT+BSO: $n=12, H / M-S o d 2^{+/-}$control: $n=9$, WT control: $n=10$.

O2. - formation: H/M-Sod2+-+BSO: $n=14$, WT+BSO: $n=13$, H/M-Sod2+/- control: $n=12$, WT control: $n=11$.

$\mathrm{H}_{2} \mathrm{O}_{2}$ formation: H/M-Sod2+--BSO: $n=7$, WT+BSO: $n=7, H / M-S o d 2^{+/-}$control: $n=6$, WT control: $n=6$.

d-ROM, derivatives of reactive oxygen metabolites; $\mathrm{H}_{2} \mathrm{O}_{2}$, hydrogen peroxide; $\mathrm{O}_{2}{ }^{-}$, superoxide. Other abbreviations as in Table 1.

Sod2 $2^{+-}+\mathrm{BSO}$ group (Figure 3D; H/M-Sod2 $2^{+-}+\mathrm{BSO}$ vs. $\mathrm{WT}+\mathrm{BSO}, \mathrm{P}=0.008 ; \mathrm{H} / \mathrm{M}-\mathrm{Sod}_{2}{ }^{+/-}+\mathrm{BSO}$ vs. $\mathrm{H} / \mathrm{M}-$ Sod2 $^{+/-}$control, $\mathrm{P}=0.003 ; \mathrm{H} / \mathrm{M}-S_{0} 2^{+/-}+\mathrm{BSO}$ vs. WT control, $\mathrm{P}=0.016$, respectively).

\section{Evaluation of Oxidative Stress}

Table 2 and Figure 4 show the expression of antioxidants and the findings of oxidative stress in the present model. Table 2 shows the total amount of glutathione in the myocardium, serum d-ROM, and the amounts of mitochondrial $\mathrm{O}_{2} \cdot{ }^{-}$and
$\mathrm{H}_{2} \mathrm{O}_{2}$ produced in the myocardium. The BSO-treated groups exhibited markedly lower total glutathione levels than the other groups (H/M-Sod2 $2^{+-}+\mathrm{BSO}$ vs. H/M-Sod2 ${ }^{+/-}$control, $\mathrm{P}=0.009$; $\mathrm{H} / \mathrm{M}-S_{0} 2^{++-}+\mathrm{BSO}$ vs. WT control, $\mathrm{P}=0.009$; WT+BSO vs. $\mathrm{H} / \mathrm{M}-S_{0} 2^{+/-}$control, $\mathrm{P}=0.009$; and $\mathrm{WT}+\mathrm{BSO}$ vs. WT control, $\mathrm{P}=0.009$, respectively). The levels of serum d-ROM were increased in the BSO-treated groups but the difference was significant only between $\mathrm{H} / \mathrm{M}-\mathrm{Sod}_{2}+-+\mathrm{BSO}$ and the controls (H/M-Sod2 $2^{+-}+\mathrm{BSO}$ vs. H/M-Sod2 $2^{+/-}$control, $\mathrm{P}=0.007$; H/MSod2 ${ }^{+/-}+\mathrm{BSO}$ vs. WT control, $\mathrm{P}=0.021$, respectively). $\mathrm{O}_{2 \cdot} \cdot$ lev- 
A

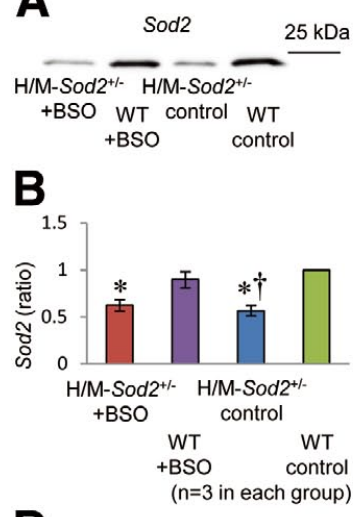

D
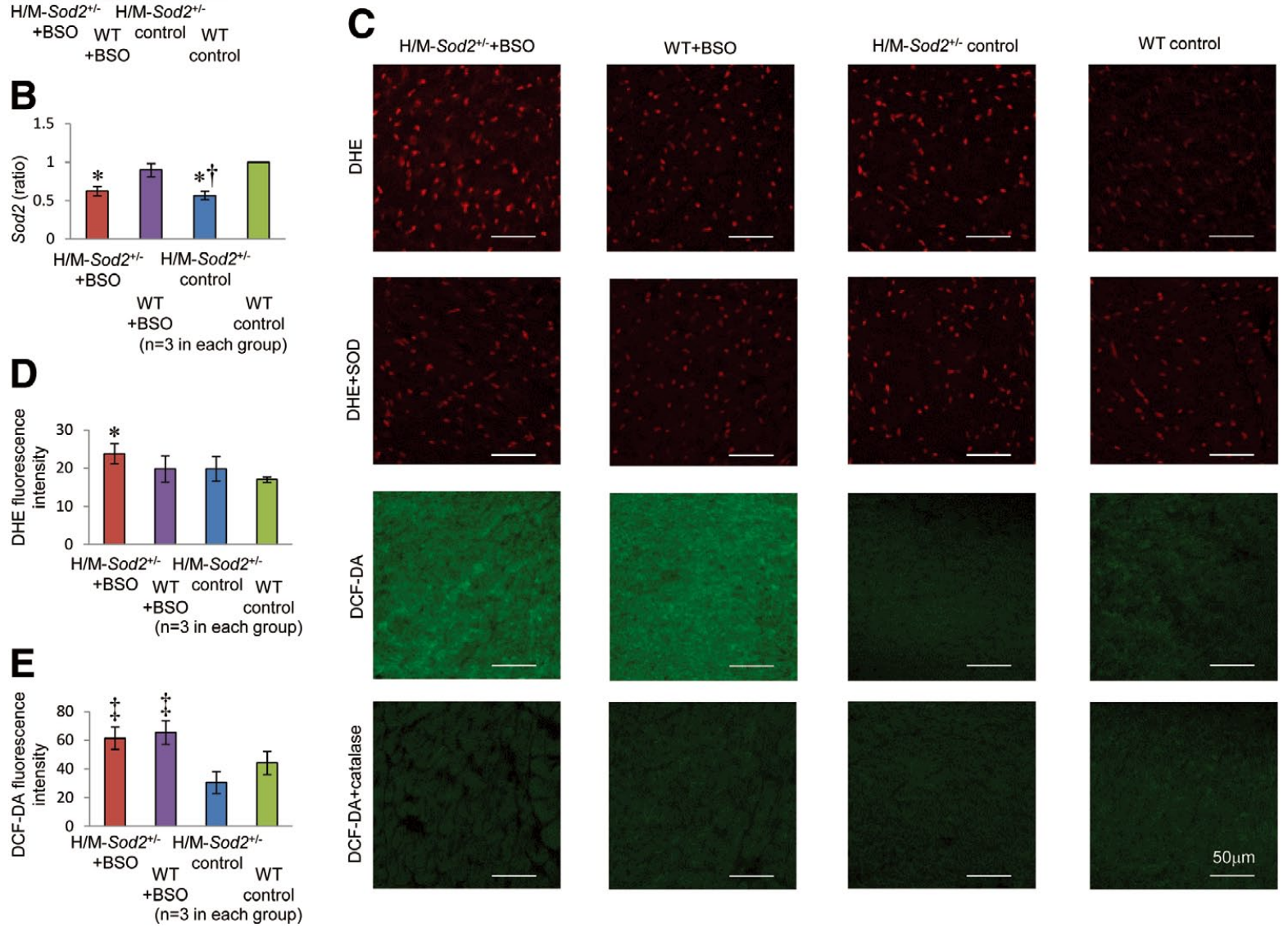

Figure 4. Evaluation of oxidative stress (2). (A) Representative examples of bands from a Western blot analysis for Sod2 in cardiac tissue. (B) Mean densities of the bands for Sod2. Sod2 expression was downregulated in both H/M-Sod2 ${ }^{+-}$groups in comparison with that in the WT groups ( $n=3$ in each group). ${ }^{*} \mathrm{P}<0.05$ vs. WT control. ${ }^{\mathrm{P}} \mathrm{P}<0.05 \mathrm{vs}$. WT+BSO. (C) Representative examples of DHE and DCF-DA staining. DHE was clearly stained in the nuclei of the myocardial cells in the H/M-Sod2+l- $+\mathrm{BSO}$ group, and was negated by pre-incubation with PEG-SOD. DCF-DA was stained in the cytoplasm of the myocardial cells in the BSOtreated groups. The fluorescence of DCF-DA was reduced by pre-incubation with PEG-catalase. (D) Mean fluorescence intensity of DHE staining. The fluorescence intensity of DHE staining was higher in the H/M-Sod2+/-+BSO group than in the WT control group ( $n=3$ in each group). ${ }^{*} P<0.05$ vs. WT control. (E) Mean fluorescence intensity of DCF-DA staining. The fluorescence intensity of DCF-DA staining was higher in the BSO-treated groups than in the H/M-Sod2+/- control group ( $\mathrm{n}=3$ in each group). $\neq \mathrm{P}<0.05$ vs. $\mathrm{H} / \mathrm{M}$-Sod2+- control. See text for discussion. H/M-Sod2+-, heterozygous heart/muscle-specific manganese superoxide dismutasedeficient mice; Sod2, superoxide dismutase 2; BSO, L-buthionine-sulfoximine; WT, wild type; DHE, fluorescent dihydroethydium; DCF-DA, 5-(and 6-)chloromethyl-2', 7'-dichlorodihydrofluorescein diacetate, acetyl ester; PEG-SOD, polyethylene glycol-superoxide dismutase.

els were increased in the H/M-Sod2 $2^{+-}+\mathrm{BSO}$ group in comparison with those in the WT+BSO group $(\mathrm{P}=0.029)$, and $\mathrm{H}_{2} \mathrm{O}_{2}$ levels were increased in the $\mathrm{H} / \mathrm{M}-\mathrm{Sod}_{2}{ }^{+/}+\mathrm{BSO}$ group compared with those in the WT+BSO and WT control groups $(\mathrm{P}=0.006$ and $\mathrm{P}=0.022$, respectively). Figure $4 \mathrm{~A}$ shows representative examples of bands from the Western blot analysis for Sod2 in cardiac tissue, and Figure 4B shows the mean densities of the bands of the Western blot for Sod2. Sod2 expression was downregulated in the H/M-Sod2 $2^{+-}$groups in comparison with the WT groups (H/M-Sod2 $2^{+/-}+\mathrm{BSO}$ vs. WT control, $\mathrm{P}=0.037 ; \mathrm{H} / \mathrm{M}-S_{0} 2^{+/-}$control vs. WT control, $\mathrm{P}=0.037 ; \mathrm{H} / \mathrm{M}-S_{\text {Sod2 }}{ }^{+-}$control vs. $\mathrm{WT}+\mathrm{BSO}, \mathrm{P}=0.049$, respectively). Figure $4 \mathrm{C}$ shows representative examples of $\mathrm{DHE}$ and DCF-DA staining. Figures $4 \mathrm{D}$ and $4 \mathrm{E}$ show the mean fluores- cence intensities of DHE and DCF-DA staining in each group, respectively. DHE was clearly stained in the nuclei of the myocardial cells in the H/M-Sod2 $2^{+/-}+\mathrm{BSO}$ group, and the staining was negated by pre-incubation with PEG-SOD, providing clear evidence for the presence of increased $\mathrm{O}_{2} \cdot{ }^{-}$. The fluorescence intensity of the DHE staining was higher in the $\mathrm{H} / \mathrm{M}-$ Sod $^{+/-}+\mathrm{BSO}$ than the WT control group $(\mathrm{P}=0.049)$. DCF-DA was stained in the cytoplasm of the myocardial cells in the BSO-treated groups. The fluorescence of DCF-DA was reduced by pre-incubation with $\mathrm{PEG}$-catalase, indicating increased $\mathrm{H}_{2} \mathrm{O}_{2}$ formation. The fluorescence intensities of DCFDA staining were higher in the BSO-treated groups than in the $\mathrm{H} / \mathrm{M}-\operatorname{Sod}_{2}{ }^{+-}$control $(\mathrm{P}=0.049$ and $\mathrm{P}=0.049$, respectively $)$. 
Table 3. Absolute Copy Numbers of Ion Channel and Cardiac Transporter Genes in RT-PCR

\begin{tabular}{|c|c|c|c|c|c|}
\hline Gene & & $\begin{array}{c}\text { H/M-Sod2+1-+BSO } \\
(n=4)\end{array}$ & $\begin{array}{c}\text { WT+BSO } \\
(n=6)\end{array}$ & $\begin{array}{c}\text { H/M-Sod2+/- control } \\
(n=4)\end{array}$ & $\begin{array}{l}\text { WT control } \\
(n=5)\end{array}$ \\
\hline Kv1.5 & $\times 10^{3}$ & $6.94 \pm 1.29$ & $4.62 \pm 0.43$ & $6.73 \pm 0.68$ & $6.19 \pm 0.64$ \\
\hline Kv2.1 & $\times 10^{4}$ & $6.15 \pm 1.67$ & $3.92 \pm 0.52$ & $6.09 \pm 0.77^{\star}$ & $3.53 \pm 0.27$ \\
\hline Kv4.2 & $\times 10^{3}$ & $8.21 \pm 0.67^{*}$ & $8.19 \pm 0.33^{*}, \neq$ & $12.9 \pm 1.36$ & $10.1 \pm 0.74$ \\
\hline Kv4.3 & $\times 10^{2}$ & $8.56 \pm 0.83^{*}$ & $11.18 \pm 1.45$ & $11.59 \pm 0.65$ & $14.96 \pm 2.09$ \\
\hline erg & $\times 10^{4}$ & $7.86 \pm 0.61^{\dagger}$ & $10.30 \pm 0.88$ & $9.44 \pm 0.72$ & $10.30 \pm 1.26$ \\
\hline KChIP2 & $\times 10^{4}$ & $3.32 \pm 0.38^{*}$ & $4.14 \pm 0.23$ & $3.91 \pm 0.45$ & $4.40 \pm 0.28$ \\
\hline Kir2.1 & $\times 10^{5}$ & $2.73 \pm 0.36$ & $2.58 \pm 0.29$ & $2.88 \pm 0.33$ & $2.51 \pm 0.34$ \\
\hline Kir2.2 & $\times 10^{5}$ & $2.60 \pm 0.46$ & $2.40 \pm 0.24$ & $2.56 \pm 0.16$ & $2.45 \pm 0.17$ \\
\hline $\mathrm{L}-\mathrm{Ca}^{2+}$ & $\times 10^{4}$ & $1.66 \pm 0.10$ & $1.78 \pm 0.18$ & $2.16 \pm 0.20$ & $2.05 \pm 0.18$ \\
\hline SCN5A & $\times 10^{4}$ & $2.14 \pm 0.19$ & $2.58 \pm 0.42$ & $2.41 \pm 0.11$ & $2.80 \pm 0.31$ \\
\hline Connexin 43 & $\times 10^{4}$ & $7.46 \pm 0.68^{*, \neq}$ & $9.81 \pm 0.85$ & $10.24 \pm 0.87$ & $10.20 \pm 0.67$ \\
\hline GAPDH & $\times 10^{6}$ & $3.91 \pm 0.21$ & $4.22 \pm 0.16$ & $4.23 \pm 0.50$ & $3.90 \pm 0.23$ \\
\hline
\end{tabular}

erg, ether-a-go-go-related gene; GAPDH, glyceraldehyde-3-phosphate dehydrogenase; KChIP2, $\mathrm{K}^{+}$channel-interacting protein-2; L-Ca' ${ }^{2+}$ L-type $\mathrm{Ca}^{2+}$ channel; SCN5A, sodium channel, voltage-gated, type V, alpha subunit. Other abbreviations as in Table 1.

${ }^{*} \mathrm{P}<0.05$ vs. WT control. $\neq \mathrm{P}<0.05$ vs. H/M-Sod2 ${ }^{+/}$control. ${ }^{\mathrm{t}} \mathrm{P}<0.05$ vs. WT+BSO.

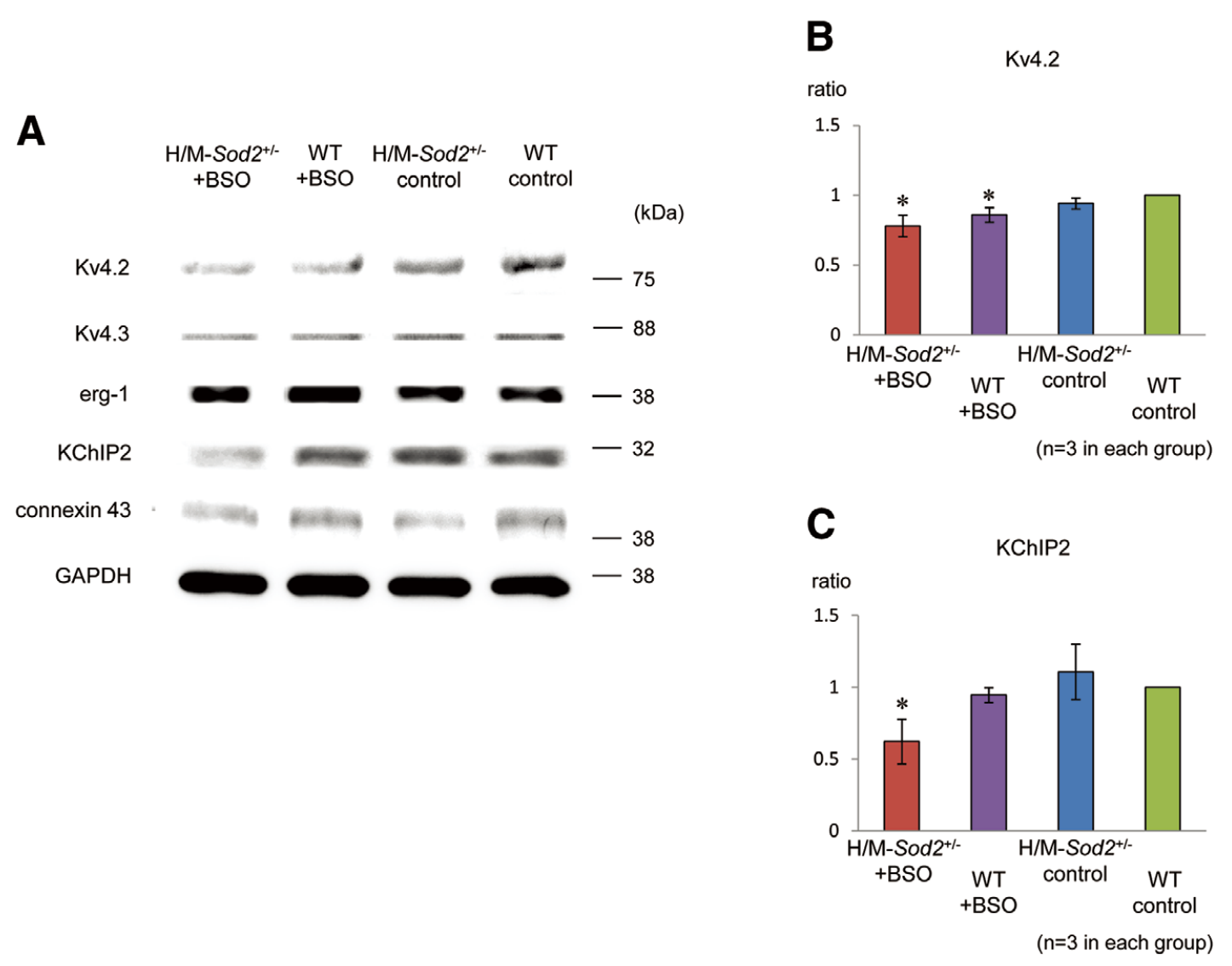

Figure 5. Western blot analysis of downregulated molecules in hyperoxidative mice. This figure shows the results of a Western blot analysis of potassium channels, KChIP2 and connexin 43. (A) Representative examples of each band in the Western blot analysis. (B) Mean densities of the bands for Kv4.2. The expression of Kv4.2 was downregulated in both BSO-treated groups in comparison with the WT control. ${ }^{*} \mathrm{P}<0.05$ vs. WT control. (C) Mean densities of the bands for KChIP2. The expression of KChIP2 was downregulated only in the H/M-Sod2+- + BSO group in comparison with the WT control. ${ }^{*} P<0.05$ vs. WT control. See text for discussion. KChIP2, K+ channel-interacting protein-2; WT, wild type; BSO, L-buthionine-sulfoximine; H/M-Sod2+/-, heterozygous heart/muscle-specific manganese superoxide dismutase-deficient mice. 


\section{Changes in Expression Levels of Cardiac Remodeling- Related Molecules}

Table 3 lists the results of the RT-PCR analyses. Significant reductions were observed in the expression levels of $\mathrm{Kv} 4.2$, $\mathrm{Kv} 4.3$, erg, KChIP2 and connexin 43 in the H/M-Sod2 ${ }^{+/-}$ $+\mathrm{BSO}$ group in comparison with the controls or the $\mathrm{WT}+\mathrm{BSO}$ group. The mRNA expression of Kv4.2 was downregulated in both the $\mathrm{H} / \mathrm{M}-\operatorname{Sod} 2^{+/-}+\mathrm{BSO}$ and $\mathrm{WT}+\mathrm{BSO}$ groups compared with the controls. In contrast, Kv4.3, erg, KChIP2, and connexin 43 levels were reduced only in the $\mathrm{H} / \mathrm{M}-\mathrm{Sod}_{2}+-+\mathrm{BSO}$ group. In addition, the expression level of Kv2.1 was upregulated in the H/M-Sod2 ${ }^{+/}$control compared with that in the WT control. There was no difference among the 4 groups in the mRNA expression of Kv1.5, Kir2.1, Kir2.2, L-type $\mathrm{Ca}^{2+}$ channel $\left(\mathrm{L}-\mathrm{Ca}^{2+}\right)$, sodium channel, voltage-gated, type $\mathrm{V}$, alpha subunit (SCN5A) and GAPDH.

Figure 5 shows the results of Western blot analyses of the molecules described above. Figure $\mathbf{5 A}$ shows representative bands, and Figures 5B and 5C show the mean densities of the bands for Kv4.2 and KChIP2, respectively. The expression of $\mathrm{Kv} 4.2$ was downregulated in both BSO-treated groups in comparison with the WT controls. The expression of KChIP2 was downregulated only in the $\mathrm{H} / \mathrm{M}-\mathrm{Sod}_{2}{ }^{+-}+\mathrm{BSO}$ group. In contrast, there were no significant differences in the levels of Kv4.3, erg-1, and connexin 43 among the 4 groups.

\section{Discussion}

In the present study, we evaluated the electrical remodeling in $\mathrm{H} / \mathrm{M}-S_{-} 2^{+/-}$mice treated with $\mathrm{BSO}$, which produces cardiomyocyte-derived mitochondrial superoxide in the cardiac tissue, and made several interesting findings. First, the heart of $\mathrm{H} / \mathrm{M}-\operatorname{Sod}_{2}{ }^{+-}+\mathrm{BSO}$ mice exhibited decreases in Sod2 and total glutathione, and this resulted in the hyper-production of mitochondrial $\mathrm{O}_{2} \cdot{ }^{-}$and $\mathrm{H}_{2} \mathrm{O}_{2}$. Second, $\mathrm{H} / \mathrm{M}-\mathrm{Sod}_{2}{ }^{+-}+\mathrm{BSO}$ mice did not show any mechano-functional changes in echocardiography, but exhibited a prolongation of MAPD and ERP in comparison with the controls, which can be considered as electrical remodeling promoted by primary oxidative stress. Finally, the expression of $\mathrm{Kv} 4.2$ was downregulated in both BSOtreated groups, but the expression of KChIP2 was downregulated only in the H/M-Sod2+/- $+\mathrm{BSO}$ group.

\section{BSO-Treated H/M-Sod2+- Mice, a Model of Cardiomyocyte- Derived Primary Hyper Oxidative Stress}

We previously reported that systemic oxidative stress caused electrical remodeling and an increase in arrhythmogenicity in BSO-treated glutathione-depleted systemic hyperoxidative rats. ${ }^{7}$ However, in that model, the primary and secondary effects of oxidative stress could not be separated because a hyperoxidative state was induced in all of the systemic organs due to the suppressive effect of $\mathrm{BSO}$ on the $\gamma$-glutamylcysteine synthetase. ${ }^{15}$ Therefore, in this study, we designed a model with presenting primary hyper-production of ROS originating from mitochondria of cardiomyocytes using H/M-Sod2+mice to evaluate the effect of cardiomyocyte-derived primary oxidative stress on the cardiac tissue.

$\mathrm{O}_{2}$ - is generated in compensation for the production of adenosine triphosphate (ATP) in mitochondria and metabolized by $\operatorname{Sod} 2$ to produce $\mathrm{H}_{2} \mathrm{O}_{2}$, which is consequently converted to $\mathrm{H}_{2} \mathrm{O}$ by the actions of the oxidative stress metabolizing system including the glutathione system. ${ }^{16}$ Therefore, a malfunction of Sod2 will induce hyper-production of ROS originating from mitochondria. The H/M-Sod2 $2^{--}$mouse has been reported to exhibit heart failure with a dilated cardiomy- opathy-like condition due to a congenital hyperoxidative state in its cardiac tissue. ${ }^{8}$ In contrast, the $\mathrm{H} / \mathrm{M}-\mathrm{Sod}_{2}+-$ mouse, which was used in this study, does not show any pathological findings in cardiac tissue and HW unless it was suffering from some pathological condition, although it might exhibit some structural changes in later months. ${ }^{17}$ In this study, we added a relatively small amount of BSO as pathological stress to H/MSod2 $2^{+-}$mice and succeeded in inducing a cardiomyocyte-derived primary hyperoxidative state in the cardiac tissue. Sod 2 expression was decreased by half in $\mathrm{H} / \mathrm{M}-\mathrm{Sod}_{2}{ }^{+-}$mice, as shown in Figures $4 \mathrm{~A}$ and $4 \mathrm{~B}$, and total glutathione levels were suppressed by the BSO treatment in both WT and H/MSod2 $2^{+-}$mice, as shown in Table 2. Interestingly, the BSO treatment promoted hyper-production of both mitochondrial and cytoplasmic $\operatorname{ROS}\left(\mathrm{O}_{2} \cdot{ }^{-}\right.$and $\left.\mathrm{H}_{2} \mathrm{O}_{2}\right)$ in the hearts of $\mathrm{H} / \mathrm{M}-$ Sod $2^{+/-}$mice, whereas only cytoplasmic $\mathrm{H}_{2} \mathrm{O}_{2}$ formation was induced in WT mice (Table 2; Figures 4C-E). The serum $\mathrm{d}-\mathrm{ROM}$ level was considered to be increased in $\mathrm{H} / \mathrm{M}-\mathrm{Sod}^{+/-}$ +BSO mice as the result of such changes in ROS production. Therefore, this can be a novel model of primary and acquired hyperoxidative stress restricted to cardiac or skeletal muscles, which can be induced at any age by BSO treatment.

\section{Electrical Remodeling in Cardiomyocyte-Derived Primary Hyperoxidative Stress}

Although oxidative stress is considered to be involved in functional or structural cardiovascular remodeling in various diseased states,$^{18}$ its direct role is unclear. In our report using an experimental model of autoimmune myocarditis in rats, we have emphasized the role of oxidative stress in the electrical and structural remodeling in the acute phase of myocarditis, but the effect of oxidative stress could not be separated from various stimulations during immune and inflammatory processes. ${ }^{19}$

Our previous study using BSO-treated glutathione-depleted rats was the first to evaluate the effect of primary oxidative stress on cardiac remodeling in vivo, and revealed no structural change but there were electrophysiological changes, that is, ERP shortening and MAPD prolongation, and the downregulated expression of erg and sarcoendoplasmic reticulum $\mathrm{Ca}^{2+}$-ATPase 2 (SERCA2). ${ }^{7}$ In contrast, in the present study, BSO-treated H/M-Sod2 $2^{+/-}$mice exhibited ERP prolongation, MAPD prolongation and the downregulated expression of $\mathrm{Kv} 4.2$ and KChIP2 in comparison with the WT control, but no significant difference was observed in the expression of erg, at least not at the protein level. The precise reason for these differences is unclear, but it might relate to the difference in the expression pattern of ROS as well as the difference in animal species. As discussed in the previous paragraph, the results in the former model might have been primary changes but were caused by systemic oxidative stress, while those in the latter model are considered to have been induced by primary hyperROS formation restricted to the cardiac and skeletal muscles. From the results of these 2 studies, the initial effect of primary oxidative stress on cardiomyocytes could perhaps be summarized as ERP and MAPD prolongation. Although WT+BSO mice exhibited some changes in electrophysiological properties, the degree of change was much smaller than in H/MSod $2^{+-}+\mathrm{BSO}$ mice. This can probably be explained by the difference in the intensity of the oxidative stress in the cardiac tissue, because mitochondrial $\mathrm{O}_{2}-{ }^{-}$and $\mathrm{H}_{2} \mathrm{O}_{2}$ production should be more enhanced in cardiomyocytes in $\mathrm{H} / \mathrm{M}-\mathrm{Sod}_{2}{ }^{+-}+\mathrm{BSO}$ mice, and the effect of systemic oxidative stress on the cardiac tissue would be limited in WT+BSO mice. Although the amount of BSO used in this study was relatively small, one 
would expect that such treatment would also induce myocardial hyper-production of ROS. In accordance with the findings of DCF-DA staining, hyper-production of $\mathrm{H}_{2} \mathrm{O}_{2}$ might occur even in the cytoplasm of the myocardial cells of WT+BSO mice. However, in the measurement of $\mathrm{O}_{2} \cdot{ }^{-}$or $\mathrm{H}_{2} \mathrm{O}_{2}$ production, a hyper-ROS state was not observed, at least in the mitochondrial fraction of the myocardium, so it was considered that a myocardial mitochondria-derived hyper-ROS state was not induced in WT+BSO mice. Because prolongation of ERP and MAPD 90 was observed only in the H/M-Sod2 $2^{+-}+\mathrm{BSO}$ mice, primary hyper-ROS production was considered to induce electrical remodeling independently of the structural remodeling or cellular dysfunction of the myocardium.

\section{Mechanism Responsible for the Changes in Electrophysiological Properties}

Although the direction of change in ERP and MAPD was opposite in the BSO-treated glutathione-depleted rats, ${ }^{7}$ both ERP and MAPD were prolonged in the H/M-Sod $2^{+/-}+\mathrm{BSO}$ mice in the present study. The prolongation of ERP coincides with the marked prolongation of MAPD 90 , and the prolongation of $\mathrm{MAPD}_{20}$ is reflected in the change in the shape of the MAP trace (Figure 3A). These MAPD prolongations can be explained by decreases in outward potassium currents, and significant reductions were observed in Kv4.2 and KChIP2 levels in the present study. KChIP2 is known to regulate the expression and function of Kv4.2 and $\mathrm{Kv} 4.3,{ }^{20-22}$ and its downregulation will result in an enhanced decay of Ito, a prolonged action potential duration, and an increase in arrhythmogenicity. ${ }^{23}$ These results are compatible with several reports of the downregulation of Ito or Ito-related molecules under conditions with hyperoxidative stress. ${ }^{15,24,25}$ Because Ito is a major regulator of action potential duration in rodents, it has been reported that the downregulation of Ito caused prolongation of $\mathrm{APD}_{50}$ or $\mathrm{APD}_{90}$ in a dominant-negative Kv4.2 channel mouse model. ${ }^{26}$ It is supposed that the prolongation of MAPD 90 can also be explained by changes in the expression of Ito-related molecules. It was reported that intracellular $\mathrm{Ca}^{2+}$ load, increase of calcineurin, or oxidation of CaMKII causes activation or overexpression of CaMKII. ${ }^{27-29}$ These reactions produce the downregulation of $\mathrm{KChIP} 2$ and $\mathrm{Kv} 4.2$, decrease of Ito, fast, and prolongation of ADP. ${ }^{27,28,30}$ It is suggested that these mechanisms affected the downregulation of KChIP2 and Kv4.2 in the present model.

In addition, Kv1.5 and Kv2.1 form the IK, slow current and are also related to the later part of the repolarization process in mouse myocardium. ${ }^{31,32}$ MAPD 90 was prolonged only in H/MSod $2^{+-}+\mathrm{BSO}$ mice in the present study, although there were no significant differences in Kv1.5 and Kv2.1 expression in $\mathrm{H} / \mathrm{M}-\operatorname{Sod} 2^{+/-}+\mathrm{BSO}$ mice, so it is supposed that the prolongation of MAPD90 was not caused by changes of Kv1.5 and Kv2.1. Similarly, Kir2.1 and Kir2.2, which form the IK1 current, and $\mathrm{L}-\mathrm{Ca}^{2+}$ did not show significant differences among the 4 groups, which suggested that these channels were not related to the prolongation of MAPD.

It was reported that oxidative stress would reduce the expression of connexin 43, and result in the alteration of ventricular electrical conduction and lethal cardiac arrhythmias. ${ }^{33}$ Although ventricular remodeling with diffuse myocardial fibrosis and the downregulated expression of connexin 43 were reported in the H/M-Sod $2^{-/-}$mouse heart, ${ }^{9} \mathrm{H} / \mathrm{M}-\operatorname{Sod} 2^{+/-}+\mathrm{BSO}$ mice did not show such changes in this study. The precise mechanisms responsible for these differences are unclear, but might be explained by the intensity and duration of hyperoxidative stress. Different from that in the H/M-Sod2 ${ }^{-1-}$ mice, the oxidative stress in the $\mathrm{H} / \mathrm{M}-\operatorname{Sod} 2^{+/-}+\mathrm{BSO}$ mice is acquired only after the BSO treatment, and the intensity of the stress might be weak because the inhibition of Sod2 is incomplete.

\section{Study Limitations}

First, the electrophysiological properties of cardiomyocytes could not be evaluated by the patch-clamp method because the number of available cells for this method was extremely limited, probably because of SOD mutation and BSO treatment. Second, although the gradient of Ito was also important in terms of affecting arrhythmogenicity, the distribution of KChIP2 and potassium channels in myocardium could not be examined in the present study.

\section{Conclusions}

We produced a unique model of primary and acquired hyperoxidative stress restricted to cardiac or skeletal muscles by using $\mathrm{H} / \mathrm{M}-\mathrm{Sod} 2^{+/-}+\mathrm{BSO}$ mice. The cardiomyocyte-derived mitochondrial superoxide caused electrical remodeling, characterized by a prolongation of MAPD and ERP. The downregulation of Kv4.2 and KChIP2 expression might be involved as a mechanism of cardiac remodeling in this model of primary oxidative stress.

\section{Acknowledgments}

The authors gratefully acknowledge the experimental co-ordination of Yusuke Ozawa from the Tokyo Metropolitan Institute of Gerontology. This study was also supported by JSPS KAKENHI Grant Number 23591061, 25860617, and a grant to the Research Committee for Epidemiology and Etiology of Idiopathic Cardiomyopathy from the Ministry of Health, Labour and Welfare of Japan.

\section{Disclosures}

Conflict of Interest: none declared.

\section{References}

1. Dhalla NS, Elmoselhi AB, Hata T, Makino N. Status of myocardial antioxidants in ischemia-reperfusion injury. Cardiovasc Res 2000; 47: 446-456.

2. Han Y, Zhao H, Tang H, Li X, Tan J, Zeng Q, et al. 20-Hydroxyeicosatetraenoic acid mediates isolated heart ischemia/reperfusion injury by increasing NADPH oxidase-derived reactive oxygen species production. Circ J 2013; 77: 1807-1816.

3. Sano M. Multifaceted approach to analyzing the pathogenesis of cardiovascular disease. Circ J 2012; 76: 2521-2529.

4. Ide T, Tsutsui H, Kinugawa S, Suematsu N, Hayashidani S, Ichikawa $\mathrm{K}$, et al. Direct evidence for increased hydroxyl radicals originating from superoxide in the failing myocardium. Circ Res 2000; 86: 152157.

5. Singh N, Dhalla AK, Seneviratne C, Singal PK. Oxidative stress and heart failure. Mol Cell Biochem 1995; 147: 77-81.

6. Huang CX, Liu Y, Xia WF, Tang YH, Huang H. Oxidative stress: A possible pathogenesis of atrial fibrillation. Med Hypotheses 2009; 72: $466-467$.

7. Kurokawa S, Niwano S, Niwano H, Ishikawa S, Kishihara J, Aoyama $\mathrm{Y}$, et al. Progression of ventricular remodeling and arrhythmia in the primary hyperoxidative state of glutathione-depleted rats. Circ J 2011; 75: $1386-1393$.

8. Nojiri H, Shimizu T, Funakoshi M, Yamaguchi O, Zhou H, Kawakami $\mathrm{S}$, et al. Oxidative stress causes heart failure with impaired mitochondrial respiration. J Biol Chem 2006; 281: 33789-33801.

9. Kawakami S, Matsuda A, Sunagawa T, Noda Y, Kaneko T, Tahara S, et al. Antioxidant, EUK-8, prevents murine dilated cardiomyopathy. Circ J 2009; 73: 2125-2134.

10. Asimakis GK, Lick S, Patterson C. Postischemic recovery of contractile function is impaired in SOD2(+/-) but not SOD1(+/-) mouse hearts. Circulation 2002; 105: $981-986$.

11. Måstensson J, Meister A. Mitochondrial damage in muscle occurs after marked depletion of glutathione and is prevented by giving glutathione monoester. Proc Natl Acad Sci USA 1989; 86: 471-475.

12. Wakisaka Y, Niwano S, Niwano H, Saito J, Yoshida T, Hirasawa S, et al. Structural and electrical ventricular remodeling in rat acute 
myocarditis and subsequent heart failure. Cardiovasc Res 2004; 63: 689-699.

13. Alberti A, Bolognini L, Macciantelli D, Caratelli M. The radical cation of N, N-diethyl-para-phenylendiamine: A possible indicator of oxidative stress in biological samples. Res Chem Intermed 2000; 26: $253-267$

14. Tojo T, Ushio-Fukai M, Yamaoka-Tojo M, Ikeda S, Patrushev N, Alexander RW. Role of gp91phox (Nox2)-containing NAD(P)H oxidase in angiogenesis in response to hindlimb ischemia. Circulation 2005; 111: 2347-2355.

15. Rozanski GJ, Xu Z. Glutathione and $\mathrm{K}(+)$ channel remodeling in postinfarction rat heart. Am J Physiol Heart Circ Physiol 2002; 282: $\mathrm{H} 2346-\mathrm{H} 2355$.

16. Shimizu T, Nojiri H, Kawakami S, Uchiyama S, Shirasawa T. Model mice for tissue-specific deletion of the manganese superoxide dismutase gene. Geriatr Gerontol Int 2010; 10(Suppl 1): S70-S79.

17. Loch T, Vakhrusheva O, Piotrowska I, Ziolkowski W, Ebelt H, Braun T, et al. Different extent of cardiac malfunction and resistance to oxidative stress in heterozygous and homozygous manganesedependent superoxide dismutase-mutant mice. Cardiovasc Res 2009; 82: $448-457$.

18. Tsutsui H, Kinugawa S, Matsushima S. Mitochondrial oxidative stress and dysfunction in myocardial remodelling. Cardiovasc Res 2009; 81: 449-456.

19. Niwano S, Niwano H, Sasaki S, Fukaya H, Yuge M, Imaki R, et al. $\mathrm{N}$-acetylcysteine suppresses the progression of ventricular remodeling in acute myocarditis: Studies in an experimental autoimmune myocarditis (EAM) model. Circ J 2011; 75: 662-671.

20. Kuo HC, Cheng CF, Clark RB, Lin JJ, Lin JL, Hoshijima M, et al. A defect in the Kv channel-interacting protein 2 (KChIP2) gene leads to a complete loss of I(to) and confers susceptibility to ventricular tachycardia. Cell 2001; 107: 801-813.

21. Decher N, Uyguner O, Scherer CR, Karaman B, Yüksel-Apak M, Busch AE, et al. hKChIP2 is a functional modifier of $\mathrm{hKv} 4.3$ potassium channels: Cloning and expression of a short hKChIP2 splice variant. Cardiovasc Res 2001; 52: 255-264.

22. Akar FG, Wu RC, Deschenes I, Armoundas AA, Piacentino V 3rd, Houser SR, et al. Phenotypic differences in transient outward K+ current of human and canine ventricular myocytes: Insights into molecular composition of ventricular Ito. Am J Physiol Heart Circ Physiol 2004; 286: H602-H609.

23. Patel SP Campbell DL. Transient outward potassium current, 'Ito', phenotypes in the mammalian left ventricle: Underlying molecular, cellular and biophysical mechanisms. $J$ Physiol 2005; 569: 7-39.
24. Li X, Li S, Xu Z, Lou MF, Anding P, Liu D, et al. Redox control of $\mathrm{K}+$ channel remodeling in rat ventricle. J Mol Cell Cardiol 2006; 40: 339-349.

25. Rozanski GJ, Xu Z. A metabolic mechanism for cardiac K+ channel remodelling. Clin Exp Pharmacol Physiol 2002; 29: 132-137.

26. Wickenden AD, Lee P, Sah R, Huang Q, Fishman GI, Backx PH. Targeted expression of a dominant-negative $\mathrm{K}(\mathrm{v}) 4.2 \mathrm{~K}(+)$ channel subunit in the mouse heart. Circ Res 1999; 85: 1067-1076.

27. Song YH. A memory molecule, $\mathrm{Ca}(2+) /$ calmodulin-dependent protein kinase II and redox stress; key factors for arrhythmias in a diseased heart. Korean Circ J 2013; 43: 145-151.

28. Erickson JR, He BJ, Grumbach IM, Anderson ME. CaMKII in the cardiovascular system: Sensing redox states. Physiol Rev 2011; 91: 889-915.

29. Erickson JR, Joiner ML, Guan X, Kutschke W, Yang J, Oddis CV, et al. A dynamic pathway for calcium-independent activation of CaMKII by methionine oxidation. Cell 2008; 133: 462-474.

30. Wagner S, Hacker E, Grandi E, Weber SL, Dybkova N, Sossalla S, et al. $\mathrm{Ca} /$ calmodulin kinase II differentially modulates potassium currents. Circ Arrhythm Electrophysiol 2009; 2: 285-294.

31. Nerbonne JM, Nichols CG, Schwarz TL, Escande D. Genetic manipulation of cardiac $\mathrm{K}(+)$ channel function in mice: What have we learned, and where do we go from here? Circ Res 2001; 89: 944-956.

32. Nerbonne JM. Studying cardiac arrhythmias in the mouse--a reasonable model for probing mechanisms? Trends Cardiovasc Med 2004; 14: $83-93$.

33. Tomaselli GF. Oxidant stress derails the cardiac connexon connection. J Clin Invest 2010; 120: 87-89.

\section{Supplementary Files}

Supplementary File 1

Figure S1. Polymerase chain reaction (PCR) for the genotyping of $\mathrm{H} / \mathrm{M}-\mathrm{Sod}_{2}{ }^{--}, \mathrm{H} / \mathrm{M}-\mathrm{Sod}_{2}{ }^{+-}$and WT mice. All genotyping of the muscle creatine kinase (MCK)-Cre transgene (Cre-tg) and the superoxide dismutase 2 ( $\operatorname{Sod} 2$ ) flox was performed by PCR using genomic DNA isolated from mouse tail.

Table S1. PCR primers used for the amplification of related genes to targeted molecules

Please find supplementary file(s);

http://dx.doi.org/10.1253/circj.CJ-13-1587 